\title{
Emerging roles of gut microbiota and the immune system in the development of the enteric nervous system
}

\author{
Panagiotis S. Kabouridis ${ }^{1,2}$ and Vassilis Pachnis ${ }^{2}$ \\ 'William Harvey Research Institute, Queen Mary University London, London, United Kingdom. 2Division of Molecular Neurobiology, MRC National Institute for Medical Research, \\ The Ridgeway, London, United Kingdom.
}

\begin{abstract}
The enteric nervous system (ENS) consists of neurons and glial cells that differentiate from neural crest progenitors. During embryogenesis, development of the ENS is controlled by the interplay of neural crest cell-intrinsic factors and instructive cues from the surrounding gut mesenchyme. However, postnatal ENS development occurs in a different context, which is characterized by the presence of microbiota and an extensive immune system, suggesting an important role of these factors on enteric neural circuit formation and function. Initial reports confirm this idea while further studies in this area promise new insights into ENS physiology and pathophysiology.
\end{abstract}

\section{Introduction}

The enteric nervous system (ENS) encompasses the intrinsic neuroglial networks of the gut, which are organized into two layers of interconnected ganglia, the outer myenteric and the inner submucosal plexus, which control virtually all aspects of gastrointestinal physiology $(1,2)$. Enteric neurons are classified into distinct subtypes according to morphological characteristics, intrinsic electrophysiological properties, or the combinatorial expression of neurotransmitters and neuropeptides such as 5-hydroxytryptamine (5-HT), calcitonin gene-related peptide (CGRP), or neuronal NOS (nNOS) (3-6). Unlike enteric neurons, which are located exclusively within enteric ganglia, enteric glial cells (EGCs) are also found within interganglionic tracts, the smooth muscle layers, and the lamina propria of the mucosa (7-9). Both lineages of the ENS are derived from neuroectodermal progenitors, which delaminate from the neural crest and colonize the gut during embryogenesis (10-14). Enteric neurogenesis commences as soon as neural crest cells invade the gut (in the mouse at around embryonic day 9.0-9.5), peaks at mid-gestation, and continues, albeit at a decreasing pace, for the remaining fetal period and early postnatal life, until it terminates after weaning (15-17). Nucleotide analog (such as BrdU) incorporation during embryogenesis in conjunction with marker analysis in adult mice has demonstrated that enteric neuron subtypes are generated during specific but overlapping periods of development. Thus, $5-\mathrm{HT}^{+}$enteric neurons are among the first to be born during embryogenesis, while $\mathrm{CGRP}^{+}$neurons are generated mostly postnatally $(18,19)$. Unlike many parts of the CNS, the period of enteric gliogenesis overlaps extensively with neurogenesis: it commences at around midgestation (when neurogenesis is at its peak) and starts to decline postnatally (17). Low levels of gliogenesis are detected in the gut throughout life, but the significance of this observation is unclear (20).

Conflict of interest: The authors have declared that no conflict of interest exists. Reference information: / Clin Invest. 2015;125(3):956-964. doi:10.1172/JCI76308.
Human genetics and gene knockout studies in rodents have identified a number of transcription factors and signaling pathways that play key roles at various stages of ENS development (21). Among them are the nuclear factors SOX10 (an SRY-related HMG-box transcription factor) and FOXD3 (a member of the forkhead protein family), which are expressed in early neural crest cells (22-26). Together with the homeodomain transcription factor PHOX2B $(27,28)$, they are required for expression of the receptor tyrosine kinase RET, which along with the glial cell linederived neurotrophic factor (GDNF) receptors $\alpha$ 1-3 (GFR $\alpha 1-3$ ) and their cognate ligands of the GDNF family of ligands (GFL), constitute a signaling pathway that is essential for ENS development (29-36). Another signaling cascade that is critical for enteric ganglia formation in the colon is the peptide endothelin-3 (ET-3) and its GPCR endothelin receptor type B (EDNRB) (37-39). Mutant forms of genes that encode critical regulators of ENS development in animal models have also been identified in familial cases of Hirschsprung disease (HSCR), a congenital neurodevelopmental abnormality that is characterized by failure of enteric ganglia formation in the distal colon and functional obstruction of the gut (40).

Although most anatomical constituents of the adult ENS form during embryogenesis, newly born enteric neurons and glia continue to be integrated into pre-existing functional neural circuits for several weeks after birth $(17,18)$. Postnatal neurogenesis and gliogenesis coincide with and almost certainly contribute to the maturation of the intrinsic neural circuits of the gut and the acquisition of spontaneous and induced motility patterns that are characteristic of adult animals (41). These observations suggest that changes in gastrointestinal physiology and environment that are associated with nutrition or the establishment of luminal microflora and the maturation of the mucosal immune system are likely to affect the postnatal phase of ENS development, particularly the late-born groups of enteric neurons. Such factors may also affect the activity of neuroglial networks and the level of consti- 
tutive gliogenesis observed in the gut of adult rodents. Therefore, the postnatal phase of ENS development constitutes an excellent model system to explore the cellular and molecular mechanisms by which environmental factors influence the assembly and activity of neural circuits. Several excellent reviews on the development of the ENS have been published recently, and the subject is covered in other articles of this series $(21,42-44)$. Here we review aspects of ENS development, focusing mainly on embryogenesis and early postnatal life, which pertain to the immune system and the microbiota of the gut lumen. This is a new and exciting area of research, and our aim is to highlight outstanding questions and provide a sense of future directions rather than present an exhaustive list of recent achievements.

\section{Coordinate development of the nervous and lymphoid systems of the gut}

The complex tissue organization and integrated function of the gut depend on the coordinated development of its constituent neuroectodermal, mesodermal, and endodermal cell lineages. Moreover, the extensive interaction of enteric neurons and glia with the highly regenerative and remodeling tissues of the gut wall, such as the intestinal epithelium (45) and mucosal vasculature (46), suggest that ENS homeostasis is integrated into the physiology of the organ. It is therefore surprising that most studies on ENS development so far have focused on the role of neural crest cell-intrinsic factors and that little attention has been paid to the formation of enteric neural circuits in the context of gut organogenesis. Moreover, very little is known about the molecular and cellular mechanisms that maintain the integrity of the ENS in adult animals and harmonize its activity with the rest of the gastrointestinal tissues.

One of the means by which functionally coupled tissues within an organ could be instructed to follow coordinated developmental programs is to respond to common signals and molecules. Such a scenario is played out between two main actors of gut organogenesis, the ENS and Peyer's patches (PPs), a major component of gut-associated lymphoid tissue. It has long been established that RET activity is essential for the survival, expansion, and differentiation of ENS progenitors (47), but a more recent report demonstrated that RET is also expressed by a hematopoietic sublineage $\left(\mathrm{CD} 4^{-} \mathrm{CD}^{-} \mathrm{c}-\mathrm{Kit}^{+} \mathrm{IL} 7 \mathrm{R} \alpha^{-} \mathrm{CD} 11 \mathrm{c}^{+}\right)$and plays a pivotal role in its ability to infiltrate the embryonic gut and form PPs (48). Interestingly, the mechanisms by which RET and its ligands are engaged by the two lineages and promote their development are distinct. While ENS development depends exclusively upon the GFR $\alpha 1$ co-receptor and its cognate GDNF ligand, hematopoietic cells employ the GFR $\alpha 3$ co-receptor and artemin, another member of the GFL family (48). Moreover, in the hematopoietic cells that form the lymphoid clusters, RET stimulation can also occur in trans by binding to co-receptor/ligand modules produced by other cells and secreted in the tissue milieu (49). This finding suggests that RET ligands and diffusible co-receptors produced by different cell types (including the ENS) provide a complex level of regulation of PP formation in the intestine.

The wider role of RET in gut organogenesis suggests that this receptor is implicated in the coordinate development of neuroglial and hematopoietic lineages in other organs. In addition to the ENS, RET is also required for the development of other branches of the autonomic nervous system, namely the sympathetic chain and parasympathetic ganglia (31, 50-56), which contact many tissues throughout the body, including cells of hematopoietic origin. Interestingly, recent reports have provided evidence that sympathetic innervation influences the development and homeostasis of hematopoietic stem cells (57), while neural input to the bone marrow inhibits the expansion of myeloproliferative neoplasms that develop in response to JAK2 mutations (58). These findings, together with a recent study demonstrating that activation of RET is required in a cell-autonomous manner to support hematopoietic stem cell survival and expansion (59), suggest that similar to the ENS paradigm, RET signaling constitutes a regulatory node that coordinates development of hematopoietic and peripheral neuronal lineages throughout the body. In that respect, it would be of great interest to examine the upstream molecular cascades that induce RET expression in such divergent cell lineages and the corresponding downstream signaling effectors activated by the receptor.

\section{Inflammatory cytokines: neurotrophic factors for the ENS?}

The interaction between the immune and nervous systems is highlighted by the broad effects of inflammatory signals on the CNS and the peripheral nervous system. For example, several members of the TNF superfamily of pro-inflammatory cytokines can modulate (positively or negatively) neurite growth during development $(60,61)$, and a more recent study has shown that TNF- $\alpha$ reverse signaling has a crucial role in establishing sympathetic innervation (62). The role of such molecules in the development and homeostasis of the ENS has not been studied extensively, but a recent report has demonstrated that the pro-inflammatory cytokines IL-1 $\beta$ and TNF- $\alpha$ promoted neurite outgrowth in a coculture model of enteric neurons and smooth muscle cells (63). In this experimental paradigm, the primary cellular target of IL-1 $\beta$ and TNF- $\alpha$ were the smooth muscle cells that were activated in an NF- $\kappa \mathrm{B}$-dependent manner to upregulate expression of GDNF. The physiological relevance of these findings is supported by the observation that conditioned medium from smooth muscle isolated from inflamed colon also promoted neurite outgrowth of cultured enteric neurons (63).

Immune cells and inflammatory responses often have contrasting effects on neural progenitors depending on the species analyzed. Thus, in mammals acute inflammation interferes with neurogenesis and the regenerative capacity of the nervous system (64). In contrast, inflammation-stimulated production of leukotrienes can promote the proliferation and differentiation of neural progenitors in zebrafish brain (65). The potential effects of cytokines or other products of the inflammatory response during normal ENS development are currently unknown; however, the ability of enteric neurons to respond to inflammatory cytokines and leukotrienes (66) raises the possibility that members of such families of signaling molecules could have an important role in the development and maturation of the mammalian ENS. Such an effect could be more pronounced in the postnatal gut during the establishment of the microbiota and the maturation of the innate and adaptive immune systems (Figure 1). 


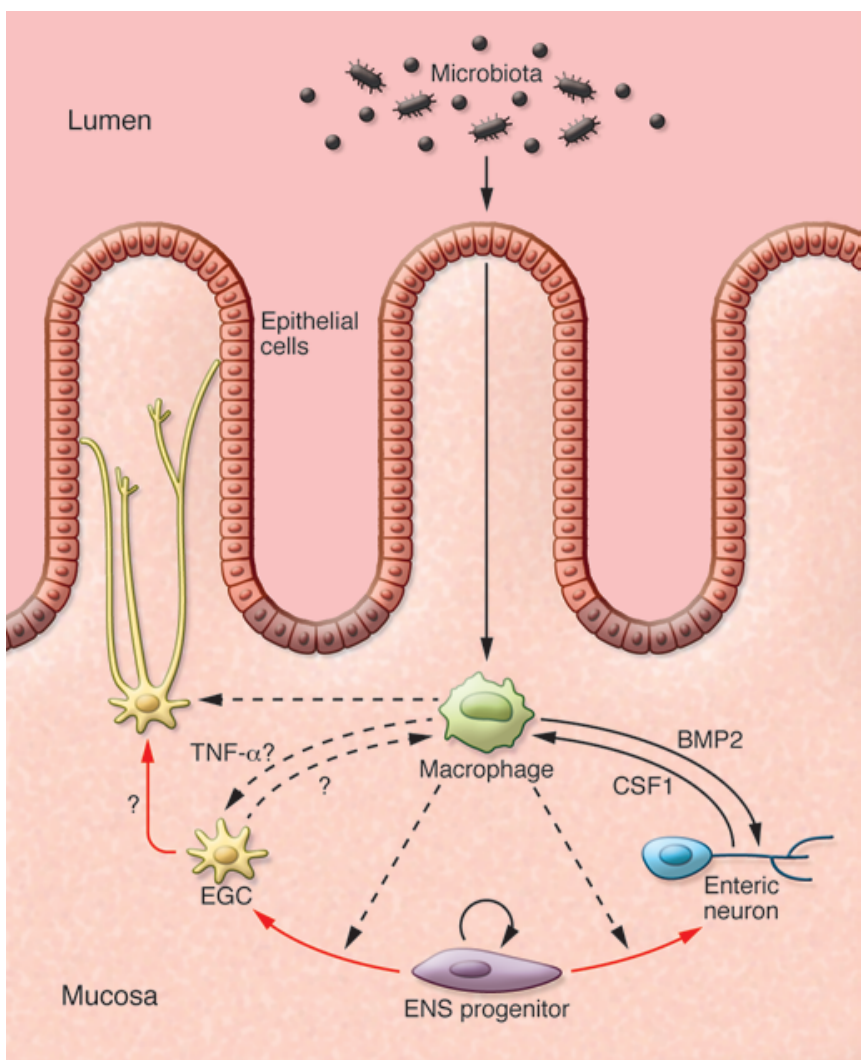

Although most studies so far have addressed the effect(s) of inflammatory processes on the nervous system, aberrant development of the nervous system may also affect the cellular networks implicated in inflammatory reactions. In that respect, a very interesting study in mice suggested that changes in neuronal subtype composition of the ENS influences the severity of gut inflammation. More specifically, mutant mice overexpressing the BMP antagonist noggin, which have a denser ENS network and underrepresentation of neurotrophin tyrosine kinase receptor type 3expressing neurons (67), developed a severe form of experimental colitis, while heart and neural crest derivatives expressed protein 2 (Hand2) haploinsufficient mice, which have reduced enteric neuron density, develop a milder form of this condition (68). At present, our understanding of the interaction between the immune system and the ENS under normal conditions or in disease states is minimal. Nevertheless, the documented effects of inflammatory cytokines on other parts of the nervous system, the extensive immune system of the gut and its activation during normal fluctuations of the microbiota, or the commonly occurring inflammatory conditions of the bowel justify an enhanced research effort in order to provide insights into neuro-immune communication during development or postnatal life.

\section{EGC development and plasticity}

Traditionally glial cells were thought to provide nourishment and mechanical support for neurons. However, it is becoming increasingly clear that glial cells also contribute to the regulation of synaptic transmission, maintenance of blood-brain barrier, and communication between the nervous and immune systems (69-71). In
Figure 1. Potential interactions between microbiota, immune cells, and ENS lineages. Immune cells, exemplified here by a macrophage, might influence the differentiation of ENS progenitors and the homeostasis of mature neurons and glial cells. In turn, enteric neurons and glia might also influence the responses of cells of the innate and adaptive immune system (136). Red arrows indicate lineage relationships. Solid black arrows indicate cell communication with known molecular mediators. Dotted black lines indicate putative interactions in vivo.

addition, glial cells show remarkable plasticity and are among the first cells to respond to injury or invasion by pathogens $(72,73)$. Although at present EGCs are the least-studied peripheral glial cells in vertebrates, there is an increasing interest in understanding the complex roles of these cells in gastrointestinal physiology.

Based on the morphology of EGCs residing within the ganglia of the myenteric plexus and expression of the glial markers glial fibrillary acidic protein (GFAP) and S100 calcium binding protein B (S100 $\beta)$, EGCs were considered generally to be the astrocyte equivalent of the gastrointestinal tract (74). However, morphologically distinct subsets of EGCs occupy enteric ganglia and extraganglionic sites, including the smooth muscle layers and the lamina propria of the intestinal mucosa $(7,8)$. In addition to the characteristically distinct morphologies, a recent ex vivo study also demonstrated the differential response of ganglionic and extraganglionic EGCs to purinergic activation (7). Nevertheless, it remains unclear whether EGC subtypes constitute molecularly and functionally distinct groups of cells with fixed properties or are capable of interconverting in response to physiological signals or pathological conditions. Clonal cultures of ENS progenitors have indicated that EGCs originate from common neuro-glial progenitors $(75,76)$, but the presence of bi-potential or committed neurogenic and gliogenic progenitors in vivo has not been documented so far. Moreover, it remains unclear whether individual progenitors are capable of generating distinct subtypes of enteric neurons and glial cells. Answering these questions will require in vivo fate mapping of sparsely labeled progenitors within the embryonic gut at different developmental stages. In rodents, a significant fraction of enteric neurons and EGCs develops during the early postnatal period, and it would be very interesting to explore how changes associated with feeding and the establishment of luminal microflora after birth affect cell fate decisions by ENS progenitors.

Ablation of enteric glia in mice using different experimental strategies has suggested a pivotal role for EGCs in maintaining gut homeostasis. Following ganciclovir-induced depletion of proliferating EGCs in Gfap::thymidine kinase transgenic mice, animals succumbed to fulminating and hemorrhaging jejunoileitis brought on by a weakened epithelial cell barrier (77). In an independent study, Cornet and colleagues also demonstrated that depletion of EGCs through expression of an autoantigen that elicits a glia-specific autoimmune response led to fatal gut inflammation and loss of bowel integrity (78). Finally, disruption of normal EGC function with the gliotoxin fluorocitrate led to reduced gastrointestinal motility specifically in the small intestine (79), although no obvious inflammation was observed in this case. These studies suggest that incomplete development or disruption of the EGC network predisposes to inflammatory pathologies in the gut that are analogous to those observed in patients with Crohn's disease. Although 
further substantiation of this idea is necessary, these studies call for additional research to elucidate the function(s) of EGCs and promise new discoveries in the field of gut pathophysiology and inflammatory bowel disease (IBD).

Most of the aforementioned studies did not focus on specific subpopulations of EGCs, but it is thought that the inflammatory pathologies associated with ablation of enteric glia are due to elimination of the diffuse network of glial cells that resides within the lamina propria of the intestinal mucosa. Indeed, it has been suggested that similar to the enhancing effects of astrocytes on the blood-brain barrier (69), these mucosal EGCS (mEGCs) play a critical role in maintaining the barrier function of the intestinal epithelium, an effect that is likely to be mediated by s-nitrosoglutathione $(80,81)$. Although further work is necessary to characterize in detail the mechanisms by which mEGCs support the barrier activity of the intestinal epithelium (82), these findings already raise interesting questions relating to the development and homeostasis of these cells. In particular, the implication of mEGCs in the host defense mechanisms against commensal or pathogenic microorganisms raises the interesting possibility that the gut microflora contributes, directly or indirectly, to the initial development and maturation of the diffuse glial cell network of the lamina propria. Moreover, given the proximity and physical interaction of mEGCs with the intestinal epithelium (45), a highly regenerative tissue in the body, it would be interesting to examine the dynamics of the population of mEGCs under normal steadystate or pathological conditions. In this respect it is interesting that in rodents, low levels of gliogenesis are detectable in the enteric ganglia of adult animals, raising the possibility that self-renewing glial progenitors of the ENS are used to generate progeny that replenish mEGCs eliminated during the natural turnover of the intestinal mucosa. The potential role of the microbiota and the mucosal immune system in the activation of glial progenitors and the homeostasis of EGCs is currently unclear, but it is interesting that other peripheral glial cells, such as Schwann cells, are capable of reprogramming to stem-like cells when challenged by leprosy bacteria, and that such reprogramming is thought to be mediated by the innate immune system $(73,83)$.

mEGCs appear to have additional and perhaps more direct effects on mucosal immunity. It has been proposed that the gliaspecific protein $S 100 \beta$ is a pro-inflammatory mediator acting via the receptor for advanced-glycation end products) to increase production of NO in the mucosa $(84,85)$. Furthermore, upon bacterial stimulation, EGCs upregulate expression of MHC class II, which suggests that they actively respond to the colonization of the gut lumen by microbiota and participate in antigen presentation to the adaptive immune system (86). In adult mice, lineage-tracing experiments under conditions of acute neuronal loss after chemical injury demonstrated that EGCs have the capacity to transdifferentiate into neurons in vivo. This occurs in the area of the myenteric plexus bordering the site of injury (17), which suggests that injury-induced inflammation might play a role in their transdifferentiation. An improved understanding of the environmental factors that influence EGC development, as well as how and why differentiated EGCs maintain a considerable degree of plasticity $(20,87,88)$, will provide important insights into the pathophysiology of gastrointestinal diseases.

\section{Microbiota influence on ENS development}

Numerous studies in both invertebrates and vertebrates have established a clear connection between microbial flora and gut physiology. In the fruit fly Drosophila melanogaster, which has a relatively simple microbiome, the presence of microbiota enhances intestinal stem cell proliferation and renewal of the gut epithelium (89). In contrast, under germ-free conditions, larvae show reduced growth and delayed pupariation, demonstrating the positive contribution of commensals to fly metabolism and energy equilibrium (90). Interestingly, controlled colonization revealed a link between certain gut commensals and mating behavior, implying a wide-ranging impact of gut microbiota on fly physiology, brain wiring, and behavior (91). Similarly in zebrafish, gut microbiota was shown to stimulate proliferation of gut epithelium and mobilization of the immune system (92), which correlated with increased fatty acid absorption (93).

Studies on mice also suggest a role of microbiota in preserving the fitness of several intestinal tissues, including the epithelium (94), the immune system (95), and the vasculature (96) as well as in controlling energy balance (97). In rodents, the gastrointestinal tract is first colonized by a "seed" microbiota obtained from the mother, which gradually changes in volume and complexity throughout the pre-weaning period and eventually matures into its stable adult composition (98, 99). For example, Lactobacillus and Prevotella species are dominant early after birth, while Bacteroidetes and Firmicutes species predominate in the adult (98). During embryogenesis the ENS develops within a largely sterile environment, but the postnatal stages of ENS development and maturation take place under drastically different conditions due to the ingestion of food and the establishment of microbiota, which result in multiple changes in the configuration of various tissues and the immune system (100). Understanding the effects of the postnatal gut environment and microbiota on the differentiation and maturation of ENS lineages and the activity of enteric neural circuits represents a research area of utmost importance.

The effect of microbiota on the formation of neural circuits in the mammalian gut is highlighted by studies of germ-free mice that demonstrated that these animals have altered spontaneous circular muscle contractions and decreased nerve density in the jejunum and ileum (101). In addition, germ-free mice showed reduced sensory neuron excitability, which was corrected following conventionalization with normal microbiota (102). In agreement with these observations, diet modifications that led to changes of microbiota composition resulted in significant alterations in gastrointestinal transit time (103).

What are the potential mechanisms by which the microbiota influences the development and organization of the ENS? The presence of microorganisms is sensed by host cells via patternrecognition receptors (PRRs), a large family of proteins that have the ability to recognize unique microbial components and play a crucial role in innate immunity and protection against pathogenic microorganisms (104). Intestinal epithelial cells and the innate immune system are the "first line of defense" against commensal or pathogenic microorganisms, and factors produced by these cell types in response to microbiota are likely to influence the development and homeostasis of the ENS (105) (see below). 
The TLRs are an important subgroup of PRRs that play a key role in the maintenance of symbiosis between gut microbiota and the host $(94,106)$. Recent expression analysis indicated that TLR3 and TLR7, which recognize viral RNA, and TLR4, which recognizes LPS, a major component of gram-negative bacteria, are expressed by enteric neurons and glia, suggesting that ENS lineages have the potential to respond directly to stimuli derived from the microbial flora (107-109). In support of this idea, in vitro studies with isolated rat myenteric plexus demonstrated a direct effect of LPS on EGCs, indicated by the increased production of the pro-inflammatory factors IL-1 and prostaglandin E2 and the consequent potentiation of bradykinin-induced intracellular $\mathrm{Ca}^{2+}$ flux in neurons (110). In a subsequent study, Anitha and colleagues demonstrated that germ-free and antibiotic-treated mice exhibited reduced motility and fewer nNOS $^{+}$neurons (111). This effect was mediated at least partly via TLR4, as $\mathrm{Tlr} 4^{-/}$mice also exhibited similar deficits in intestinal motility and had a reduced number of nitrergic neurons. Interestingly, this phenotype was reproduced in mice with ENSspecific deletion of the common TLR signal transducer MyD88 (111), suggesting that TLR4 signaling is a cell-autonomous requirement within ENS lineages. Since the vast majority of $\mathrm{nNOS}^{+}$enteric neurons are born during embryogenesis $(18,19)$, these experiments indicate that TLR4 is either required for the late expression of the molecular profile of specific subsets of enteric neurons or for their survival within the microenvironment of the postnatal gut. In support of the latter idea, Anitha and colleagues showed that LPS promoted the survival of cultured enteric neurons in an NF- $\kappa \mathrm{B}-$ dependent manner (111). It would be interesting to determine whether restoring the normal complement of microbiota in germ-free or antibiotic-treated mice is sufficient to rescue the effect of reduced TLR4/MyD88 signaling on NNOS $^{+}$enteric neurons.

TLR2, another member of the TLR family, is known to strengthen the intestinal epithelial cell barrier and prevent bacterial entry and inflammation $(94,112,113)$. Interestingly, TLR2 polymorphisms have been identified in certain cases of IBD, although the relevance of this finding to the pathogenesis of Crohn's disease or ulcerative colitis remains unclear (114). Enteric neurons and glia also express TLR2 and the myenteric ganglia of $\mathrm{Tl} 2^{-1-}$ mice contained fewer neurons compared with their wild-type counterparts, with the reduction in inhibitory $\mathrm{nNOS}^{+}$neurons being the most notable phenotype (115). The reduction in $\mathrm{nNOS}^{+}$neurons was accompanied by intestinal dysmotility and impaired chloride secretion by ileal explants. The glial markers GFAP and S100 $\beta$ were also reduced in the myenteric plexus of mutant mice, but it remains unclear whether this reflects a diminished population of EGCs in enteric ganglia or lower expression of these markers in a normal population of glial cells. Interestingly, exogenous addition of GDNF corrected many ENS deficiencies in $\mathrm{Tlr}^{-/-}$mice and in antibiotic-treated animals, suggesting that one of the roles of the microbiota/TLR2 axis is to promote the expression of neurotrophic factors that are required to maintain the functional organization of the mammalian ENS (115). Together with the demonstrated ability of pro-inflammatory cytokines such as IL- $1 \beta$ and TNF- $\alpha$, which are produced in response to TLR activation by bacterial components to stimulate production of GDNF (63), these findings argue that development and maturation of the ENS depend on the complex interplay between immune regulators and neuroregulators (Figure 1).
Although there is much to be discovered regarding the mechanisms by which the innate immune system of the gut influences ENS development and activity, the significance of these initial observations are likely to be far-reaching. For example, overstimulation of TLRs by potent or recurring intestinal infections early in life could affect the manner in which the ENS develops. On the other hand, excessive use of antibiotics early in life could perturb the timely evolution of intestinal commensals (116) and consequently hamper the maturation of the developing ENS. It is conceivable that in both cases an ENS-related pathology might develop later in life (117). The impact that changes in microbiota can have on enteric circuitry is highlighted by the effects of probiotics on the chemical coding of enteric neurons. Piglets on a diet supplemented with the probiotic Saccharomyces boulardii showed reduced numbers of calbindin ${ }^{+}$neurons (118), while those fed with Pediococcus acidilactici had an increased number of CGRPand galanin-expressing neurons in the submucosal ganglia of the ileum (119). Interestingly, the probiotic Lactobacillus paracasei was shown to attenuate visceral hypersensitivity induced by the perturbation of gut microbiota with antibiotics (120). Similarly, Lactobacillus acidophilus administration had an analgesic effect in a model of colonic hypersensitivity by inducing the expression of opioid and cannabinoid receptors (121). Finally, it has been suggested that butyrate, a short-chain fatty acid produced by microbiota, enhances neuronal excitability (122) and gastrointestinal motility (123). Although these early results are encouraging, a systematic analysis of the effects of the microbiota and nutrition on ENS development and function is still lacking. Moreover, the mechanisms by which the microenvironment of the gut lumen influences the development and organization of the neuronal and glial cell lineages of the ENS are currently unknown. Despite such limited understanding, the emerging data suggest that the developing ENS is capable of responding to environmental cues and adjusting to the volatile milieu of the gastrointestinal lumen. Reverse regulation in which the ENS contributes to the shaping of the microbiome is also possible, as suggested by a study in which alterations in the composition of colonic and fecal microbiota were observed in a mouse model of congenital aganglionosis (124). It would be interesting to determine whether differences in microbiota composition are also present in animals with more subtle primary deficits in enteric neuron connectivity and gastrointestinal motility (125) and whether such potential deficits represent direct effects of ENS circuits on microbiota or secondary consequences of abnormal peristalsis.

A concept emerging in recent years from the study of the gut microbiota and its effect on organismal physiology is its perceived influence on brain function and behavior via the "gut-brain axis" (126). Interestingly, there is a high incidence of gastrointestinal comorbidity in children with autism spectrum disorders (ASD), with the majority of patients reporting some degree of chronic constipation or diarrhea, abdominal pain, and other symptoms associated with irritable or inflammatory bowel conditions (127129). In the mouse, features of autism are recapitulated in the maternal immune activation (MIA) model, in which epithelial barrier weakening that results from robust immune system activation in pregnant mice produces offspring that display features of ASD (130). Remarkably, oral treatment of these offspring with the com- 
mensal Bacteroides fragilis restores gastrointestinal barrier integrity and ameliorates ASD defects through its capacity to rebalance the levels of certain metabolites (130). Although the effect of MIA on ENS development and function has not been studied, this work further highlights the importance of a normal microbiota gutbrain axis during development and that alterations of this axis can lead to CNS disorders.

\section{Cross-talk between the innate immune system and ENS: watch this space!}

A key component of the innate immune system of the mucosa is the population of macrophages, which perform functions related to innate and adaptive immunity and are essential for the response of gut tissues to injury and repair (131). Much of our understanding of the interaction of the innate immune system and the nervous system is based on studies of microglia, the resident macrophages of the CNS, which employ phagocytosis and the release of cytokines to regulate homeostasis under normal and inflammatory conditions (132). More recent studies have identified a role for microglia in synaptogenesis and synaptic transmission, indicating that these cells contribute to the formation and maturation of neural circuits and the pathogenesis of neurodevelopmental disorders such as ASD and schizophrenia. Remarkably, microglial cell activity can influence neural network formation not only during perinatal and postnatal stages, but also during embryogenesis (133). Macrophages are present throughout the gut, including the muscularis externa (muscularis macrophages), where they come into close contact with components of the ENS $(134,135)$. A recent study has shown that muscularis macrophages have a distinct marker expression profile (CX3CR $1{ }^{\text {hi }} \mathrm{MHCI}{ }^{\mathrm{hi}} \mathrm{CD} 11 \mathrm{c}^{\mathrm{lo}} \mathrm{CD} 103$ $\mathrm{CD}_{11} \mathrm{~b}^{+}$) and that their development and maintenance is critically dependent upon colony stimulating factor 1 (CSF1) (136). Interestingly, the ENS of CSF1-deficient animals $\left(C s f 1^{\text {op } / o p}\right)$ contained a higher number of neurons and had a less organized architecture, consistent with the idea that immune-related factors participate in the normal development of ENS (136). The functional link between ENS and muscularis macrophages was not limited to the developmental period but was also important for the steady-state function of the adult gut via a mechanism whereby macrophageproduced BMP2 regulated enteric neuron function and intestinal peristalsis, while enteric neuron-produced CSF1 maintained the number of muscularis macrophages necessary for this operation. Remarkably, the production of both mediators required the presence of the microbial flora, since antibiotic-treated mice had reduced BMP2 and CSF1 (136). This pioneering work provides a cellular and molecular cascade that links the ENS and the immune system and paves the way for more discoveries in this emerging field (Figure 1).

Developmental biologists have learned over the years that one of the ways evolution coordinates multi-tissue organ development is by employing chemical signals to influence the differentiation of neighboring cell groups. Although it is hard to imagine how the gut would escape from such rule, our understanding of how nonneuroectodermal tissues influence the assembly and function of the ENS is rather limited. The work summarized in this Review demonstrates that immune cells and their products can have profound effects on the development of neural circuits in the gut wall. It also points to the immune system as an important mechanism used by the environment (in the case of the gut, its luminal contents and microbiota) to shape the formation of neural circuits in ways that can accommodate unpredictable physiological changes and generate appropriate responses in normal or disease situations. It would be interesting to explore whether and how the ENS can also influence the development and function of the gut immune system under physiological or pathological conditions. These research areas promise to provide many discoveries in the near future, which hopefully can be translated into tangible benefits for patients with gastrointestinal disorders.

\section{Acknowledgments}

We apologize to the authors of reports that, due to space limitations, have not been included in our reference list. Work in the V. Pachnis lab is supported by the Medical Research Council (MRC UK; grant-in-aid U117537087) and the Biotechnology and Biological Sciences Research Council (BBSRC UK; grant LO22974/1).

Address correspondence to: Vassilis Pachnis, National Institute for Medical Research, Division of Molecular Neurobiology, The Ridgeway, Mill Hill, London NW7 1AA, United Kingdom. Phone: 44.20.8816.2113; E-mail:vpachni@nimr.mrc.ac.uk.
1. Gershon MD. The Second Brain. New York, New York, USA: HarperCollins Publishers, Inc.; 1998.

2. Furness J. The Enteric Nervous System. Hoboken, New Jersey, USA: Blackwell Publishing; 2006.

3. Furness JB, Costa M. The Enteric Nervous System. New York, New York, USA: Churchill Livingstone; 1987.

4. Furness JB. Types of neurons in the enteric nervous system. JAuton Nerv Syst. 2000;81(1-3):87-96.

5 . Brookes SJ. Classes of enteric nerve cells in the guinea-pig small intestine. Anat Rec. 2001;262(1):58-70.

6. Qu ZD, Thacker M, Castelucci P, Bagyanszki M, Epstein ML, Furness JB. Immunohistochemical analysis of neuron types in the mouse small intestine. Cell Tissue Res. 2008;334(2):147-161.

7. Boesmans W, Lasrado R, Vanden Berghe P, Pachnis V. Heterogeneity phenotypic plasticity of glial cells in the mammalian enteric nervous system. Glia. 2015;63(2):229-241.

8. Gulbransen BD, Sharkey KA. Novel functional roles for enteric glia in the gastrointestinal tract. Nat Rev Gastroenterol Hepatol. 2012;9(11):625-632.

9. Ruhl A. Glial cells in the gut. Neurogastroenterol Motil. 2005;17(6):777-790.

10. Druckenbrod NR, Epstein ML. The pattern of neural crest advance in the cecum and colon. Dev Biol. 2005;287(1):125-133.

11. Le Douarin NM, Teillet MA. The migration of neural crest cells to the wall of the digestive tract in avian embryo. J Embryol Exp Morphol. 1973;30(1):31-48.

12. Yntema CL, Hammond WS. The origin of intrinsic ganglia of trunk viscera from vagal neural crest in the chick embryo. J Comp Neurol. 1954;101(2):515-541.
13. Young HM, et al. Dynamics of neural crestderived cell migration in the embryonic mouse gut. Dev Biol. 2004;270(2):455-473.

14. Young HM, et al. Colonizing while migrating: how do individual enteric neural crest cells behave? BMC Biol. 2014;12:23.

15. Young HM, Bergner AJ, Muller T. Acquisition of neuronal and glial markers by neural crestderived cells in the mouse intestine. J Comp Neurol.2003;456(1):1-11.

16. Hao MM, Young HM. Development of enteric neuron diversity. J Cell Mol Med. 2009;13(7):1193-1210.

17. Laranjeira C, et al. Glial cells in the mouse enteric nervous system can undergo neurogenesis in response to injury. JClin Invest. 2011;121(9):3412-3424.

18. Pham TD, Gershon MD, Rothman TP. Time of 
origin of neurons in the murine enteric nervous system: sequence in relation to phenotype. J Comp Neurol. 1991;314(4):789-798.

19. Bergner AJ, et al. Anderson CR, Young HM. Birthdating of myenteric neuron subtypes in the small intestine of the mouse. JComp Neurol. 2014;522(3):514-527.

20. Joseph NM, He S, Quintana E, Kim YG, Nunez G, Morrison SJ. Enteric glia are multipotent in culture but primarily form glia in the adult rodent gut. J Clin Invest. 2011;121(9):3398-3411.

21. Lake JI, Heuckeroth RO. Enteric nervous system development: migration, differentiation, and disease. Am J Physiol Gastrointest Liver Physiol. 2013;305(1):G1-G24.

22. Southard-Smith EM, Kos L, Pavan WJ. Sox10 mutation disrupts neural crest development in Dom Hirschsprung mouse model. Nat Genet. 1998;18(1):60-64.

23. Paratore C, Eichenberger C, Suter U, Sommer L. Sox10 haploinsufficiency affects maintenance of progenitor cells in a mouse model of Hirschsprung disease. Hum Mol Genet. 2002;11(24):3075-3085.

24. Kapur RP. Early death of neural crest cells is responsible for total enteric aganglionosis in Sox10(Dom)/Sox10(Dom) mouse embryos. Pediatr Dev Pathol. 1999;2(6):559-569.

25. Mundell NA, et al. Enteric nervous system specific deletion of Foxd3 disrupts glial cell differentiation and activates compensatory enteric progenitors. Dev Biol. 2012;363(2):373-387.

26. Teng L, Mundell NA, Frist AY, Wang Q, Labosky PA. Requirement for Foxd3 in the maintenance of neural crest progenitors. Development. 2008;135(9):1615-1624.

27. Pattyn A, Morin X, Cremer H, Goridis C, Brunet JF. The homeobox gene Phox $2 b$ is essential for the development of autonomic neural crest derivatives. Nature. 1999;399(6734):366-370.

28. Young HM, Ciampoli D, Hsuan J, Canty AJ. Expression of Ret-, p75(NTR)-, Phox2a-, Phox $2 \mathrm{~b}-$, and tyrosine hydroxylase-immunoreactivity by undifferentiated neural crestderived cells and different classes of enteric neurons in the embryonic mouse gut. Dev Dyn. 1999;216(2):137-152.

29. Schuchardt A, D'Agati V, Larsson-Blomberg L, Costantini F, Pachnis V. Defects in the kidney and enteric nervous system of mice lacking the tyrosine kinase receptor Ret. Nature. 1994;367(6461):380-383.

30. Durbec P, et al. GDNF signalling through the Ret receptor tyrosine kinase. Nature. 1996;381(6585):789-793.

31. Durbec PL, Larsson-Blomberg LB, Schuchardt A, Costantini F, Pachnis V. Common origin and developmental dependence on c-ret of subsets of enteric and sympathetic neuroblasts. Development. 1996;122(1):349-358.

32. Hearn CJ, Murphy M, Newgreen D. GDNF and ET-3 differentially modulate the numbers of avian enteric neural crest cells and enteric neurons in vitro. Dev Biol. 1998;197(1):93-105.

33. Heuckeroth RO, Lampe PA, Johnson EM, Milbrandt J. Neurturin and GDNF promote proliferation and survival of enteric neuron and glial progenitors in vitro. Dev Biol. 1998;200(1):116-129.
34. Mulligan LM. RET revisited: expanding the oncogenic portfolio. Nat Rev Cancer. 2014;14(3):173-186.

35. Natarajan D, Marcos-Gutierrez C, Pachnis V, De Graaff E. Requirement of signalling by receptor tyrosine kinase RET for the directed migration of enteric nervous system progenitor cells during mammalian embryogenesis. Development. 2002;129(22):5151-5160.

36. Gianino S, Grider JR, Cresswell J, Enomoto H, Heuckeroth RO. GDNF availability determines enteric neuron number by controlling precursor proliferation. Development. 2003;130(10):2187-2198.

37. Hosoda K, et al. Targeted and natural (piebaldlethal) mutations of endothelin-B receptor gene produce megacolon associated with spotted coat color in mice. Cell. 1994;79(7):1267-1276.

38. McCallion AS, Stames E, Conlon RA, Chakravarti A. Phenotype variation in two-locus mouse models of Hirschsprung disease: tissue-specific interaction between Ret and Ednrb. Proc Natl Acad Sci U S A. 2003;100(4):1826-1831.

39. Barlow A, de Graaff E, Pachnis V. Enteric nervous system progenitors are coordinately controlled by the $G$ protein-coupled receptor EDNRB and the receptor tyrosine kinase RET. Neuron. 2003;40(5):905-916.

40. Amiel J, et al. Hirschsprung disease, associated syndromes and genetics: a review. JMed Genet 2008;45(1):1-14.

41. Roberts RR, Murphy JF, Young HM, Bornstein JC. Development of colonic motility in the neonatal mouse-studies using spatiotemporal maps. Am J Physiol Gastrointest Liver Physiol. 2007;292(3):G930-G938.

42. Hao MM, Bornstein JC, Vanden Berghe P, Lomax AE, Young HM, Foong JP. The emergence of neural activity and its role in the development of the enteric nervous system. Dev Biol. 2013;382(1):365-374.

43. Obermayr F, Hotta R, Enomoto H, Young HM Development and developmental disorders of the enteric nervous system. Nat Rev Gastroenterol Hepatol. 2013;10(1):43-57.

44. Goldstein AM, Hofstra RM, Burns AJ. Building a brain in the gut: development of the enteric nervous system. Clin Genet. 2013;83(4):307-316.

45. Bohorquez DV, Samsa LA, Roholt A, Medicetty S, Chandra R, Liddle RA. An enteroendocrine cellenteric glia connection revealed by $3 \mathrm{D}$ electron microscopy. PLoS One. 2014;9(2):e89881.

46. Kabouridis PS, et al. Microbiota controls the homeostasis of glial cells in the gut lamina propria. Neuron. 2015;85(2):289-295

47. Gershon MD. Developmental determinants of the independence and complexity of the enteric nervous system. Trends Neurosci. 2010;33(10):446-456

48. Veiga-Fernandes $\mathrm{H}$, et al. Tyrosine kinase receptor RET is a key regulator of Peyer's patch organogenesis. Nature. 2007;446(7135):547-551.

49. Patel A, et al. Differential RET signaling pathways drive development of the enteric lymphoid and nervous systems. Sci Signal. 2012;5(235):ra55.

50. Honma Y, et al. Artemin is a vascular-derived neurotropic factor for developing sympathetic neurons. Neuron. 2002;35(2):267-282.

51. Nishino J, et al. GFR alpha3, a component of the artemin receptor, is required for migration and survival of the superior cervical ganglion. Neuron. 1999;23(4):725-736.

52. Ernsberger U. The role of GDNF family ligand signalling in the differentiation of sympathetic and dorsal root ganglion neurons. Cell Tissue Res. 2008;333(3):353-371

53. Heuckeroth RO, et al. et al. Gene targeting reveals a critical role for neurturin in the development and maintenance of enteric, sensory, and parasympathetic neurons. Neuron. 1999;22(2):253-263.

54. Enomoto H, Heuckeroth RO, Golden JP, Johnson EM, Milbrandt J. Development of cranial parasympathetic ganglia requires sequential actions of GDNF and neurturin. Development. 2000;127(22):4877-4889.

55. Hashino E, et al. GDNF and neurturin are target-derived factors essential for cranial parasympathetic neuron development. Development. 2001;128(19):3773-3782.

56. Rossi J, Tomac A, Saarma M, Airaksinen MS. Distinct roles for GFR $\alpha 1$ and GFR $\alpha 2$ signalling in different cranial parasympathetic ganglia in vivo. Eur J Neurosci. 2000;12(11):3944-3952.

57. Katayama Y, et al. Signals from the sympathetic nervous system regulate hematopoietic stem cell egress from bone marrow. Cell. 2006;124(2):407-421.

58. Arranz L, et al. Neuropathy of haematopoietic stem cell niche is essential for myeloproliferative neoplasms. Nature. 2014;512(7512):78-81.

59. Fonseca-Pereira D, et al. The neurotrophic factor receptor RET drives haematopoietic stem cell survival function. Nature. 2014;514(7520):98-101

60. Neumann H, Schweigreiter R, Yamashita $T$, Rosenkranz K, Wekerle H, Barde YA. Tumor necrosis factor inhibits neurite outgrowth and branching of hippocampal neurons by a rho-dependent mechanism. J Neurosci. 2002;22(3):854-862.

61. Gutierrez H, Kisiswa L, O’Keeffe GW, Smithen MJ, Wyatt S, Davies AM. Regulation of neurite growth by tumour necrosis superfamily member RANKL. Open Biol. 2013;3(1):120150.

62. Kisiswa L, Osorio C, Erice C, Vizard T, Wyatt S, Davies AM. TNF $\alpha$ reverse signaling promotes sympathetic axon growth and target innervation. Nat Neurosci. 2013;16(7):865-873

63. Gougeon PY, Lourenssen S, Han TY, Nair DG, Ropeleski MJ, Blennerhassett MG. The proinflammatory cytokines IL-1 $\beta$ and $\mathrm{TNF} \alpha$ are neurotrophic for enteric neurons. J Neurosci. 2013;33(8):3339-3351.

64. Iosif RE, et al. Tumor necrosis factor receptor 1 is a negative regulator of progenitor proliferation in adult hippocampal neurogenesis. J Neurosci. 2006;26(38):9703-9712.

65. Kyritsis N, et al. Acute inflammation initiates the regenerative response in the adult zebrafish brain. Science. 2012;338(6112):1353-1356.

66. Liu S, et al. Actions of cysteinyl leukotrienes in the enteric nervous system of guinea-pig stomach and small intestine. Eur J Pharmacol. 2003;459(1):27-39.

67. Chalazonitis A, et al. Bone morphogenetic protein-2 and -4 limit the number of enteric neurons but promote development of a TrkC-expressing neurotrophin-3-dependent subset. J Neurosci. 
2004;24(17):4266-4282.

68. Margolis KG, et al. Enteric neuronal density contributes to the severity of intestinal inflammation. Gastroenterology. 2011;141(2):588-598.

69. Alvarez JI, Katayama T, Prat A. Glial influence on the blood brain barrier. Glia. 2013;61(12):1939-1958.

70. Clarke LE, Barres BA. Emerging roles of astrocytes in neural circuit development. Nat Rev Neurosci. 2013;14(5):311-321.

71. Jensen CJ, Massie A, De Keyser J. Immune players in the CNS: the astrocyte. J Neuroimmune Pharmacol. 2013;8(4):824-839.

72. Bardehle S, et al. Live imaging of astrocyte responses to acute injury reveals selective juxtavascular proliferation. Nat Neurosci. 2013;16(5):580-586.

73. Masaki T, Qu J, Cholewa-Waclaw J, Burr K, Raaum R, Rambukkana A. Reprogramming adult Schwann cells to stem cell-like cells by leprosy bacilli promotes dissemination of infection. Cell. 2013;152(1-2):51-67.

74. Jessen KR, Mirsky R. Astrocyte-like glia in the peripheral nervous system: an immunohistochemical study of enteric glia. J Neurosci. 1983;3(11):2206-2218.

75. Bixby S, Kruger GM, Mosher JT, Joseph NM, Morrison SJ. Cell-intrinsic differences between stem cells from different regions of the peripheral nervous system regulate the generation of neural diversity. Neuron. 2002;35(4):643-656.

76. Bondurand N, Natarajan D, Thapar N, Atkins C, Pachnis V. Neuron and glia generating progenitors of the mammalian enteric nervous system isolated from foetal and postnatal gut cultures. Development. 2003;130(25):6387-6400.

77. Bush TG, et al. Fulminant jejuno-ileitis following ablation of enteric glia in adult transgenic mice. Cell. 1998;93(2):189-201.

78. Cornet A, et al. Enterocolitis induced by autoimmune targeting of enteric glial cells: a possible mechanism in Crohn's disease? Proc Natl Acad Sci U S A. 2001;98(23):13306-13311.

79. Nasser $Y$, et al. Role of enteric glia in intestinal physiology: effects of the gliotoxin fluorocitrate on motor and secretory function. Am J Physiol Gastrointest Liver Physiol. 2006;291(5):G912-G927.

80. Savidge TC, et al. Enteric glia regulate intestinal barrier function and inflammation via release of S-nitrosoglutathione. Gastroenterology. 2007;132(4):1344-1358.

81. Flamant M, et al. Enteric glia protect against Shigella flexneri invasion in intestinal epithelial cells: a role for S-nitrosoglutathione. Gut. 2011;60(4):473-484.

82. Neunlist M, Van Landeghem L, Mahe MM, Derkinderen P, des Varannes SB, Rolli-Derkinderen $M$. The digestive neuronal-glial-epithelial unit: a new actor in gut health and disease. Nat Rev Gastroenterol Hepatol. 2013;10(2):90-100.

83. Masaki T, McGlinchey A, Cholewa-Waclaw J, Qu J, Tomlinson SR, Rambukkana A. Innate immune response precedes Mycobacterium lepraeinduced reprogramming of adult Schwann cells. Cell Reprogram. 2014;16(1):9-17.

84. Cirillo C, et al. Increased mucosal nitric oxide production in ulcerative colitis is mediated in part by the enteroglial-derived S100B protein. Neurogastroenterol Motil. 2009;21(11):1209-e112.
85. Esposito G, et al. Enteric glial-derived S100B protein stimulates nitric oxide production in celiac disease. Gastroenterology. 2007;133(3):918-925.

86. Turco F, et al. Enteroglial-derived S100B protein integrates bacteria-induced Toll-like receptor signalling in human enteric glial cells. Gut. 2014;63(1):105-115.

87. Heanue TA, Pachnis V. Prospective identification and isolation of enteric nervous system progenitors using Sox2. Stem Cells. 2011;29(1):128-140.

88. Neunlist M, et al. Enteric glial cells: recent developments and future directions. Gastroenterology. 2014;147(6):1230-1237.

89. Buchon N, Broderick NA, Chakrabarti S, Lemaitre B. Invasive and indigenous microbiota impact intestinal stem cell activity through multiple pathways in Drosophila. Genes Dev. 2009;23(19):2333-2344.

90. Shin SC, et al. Drosophila microbiome modulates host developmental and metabolic homeostasis via insulin signaling. Science. 2011;334(6056):670-674

91. Sharon G, Segal D, Ringo JM, Hefetz A, ZilberRosenberg I, Rosenberg E. Commensal bacteria play a role in mating preference of Drosophila melanogaster. Proc Natl Acad Sci US A. 2010;107(46):20051-20056.

92. Rawls JF, Samuel BS, Gordon JI. Gnotobiotic zebrafish reveal evolutionarily conserved responses to the gut microbiota. Proc Natl Acad Sci U S A. 2004;101(13):4596-4601.

93. Semova I, et al. Microbiota regulate intestinal absorption and metabolism of fatty acids in the zebrafish. Cell Host Microbe. 2012;12(3):277-288.

94. Rakoff-Nahoum S, Paglino J, Eslami-Varzaneh F, Edberg S, Medzhitov R. Recognition of commensal microflora by toll-like receptors is required for intestinal homeostasis. Cell. 2004;118(2):229-241.

95. Belkaid Y, Hand TW. Role of the microbiota in immunity and inflammation. Cell. 2014;157(1):121-141.

96. Stappenbeck TS, Hooper LV, Gordon JI. Developmental regulation of intestinal angiogenesis by indigenous microbes via Paneth cells. Proc Natl Acad Sci U S A . 2002;99(24):15451-15455.

97. Turnbaugh PJ, Backhed F, Fulton L, Gordon JI. Diet-induced obesity is linked to marked but reversible alterations in the mouse distal gut microbiome. Cell Host Microbe. 2008;3(4):213-223.

98. Nicholson JK, et al. Host-gut microbiota metabolic interactions. Science. 2012;336(6086):1262-1267.

99. Koenig JE, et al. Succession of microbial consortia in the developing infant gut microbiome. Proc Natl Acad Sci U S A. 2011;108(suppl 1):4578-4585.

100. Hooper LV, Littman DR, Macpherson AJ. Interactions between the microbiota and the immune system. Science. 2012;336(6086):1268-1273.

101.Collins J, Borojevic R, Verdu EF, Huizinga JD, Ratcliffe EM. Intestinal microbiota influence the early postnatal development of the enteric nervous system. Neurogastroenterol Motil. 2014;26(1):98-107.

102. McVey Neufeld KA, Mao YK, Bienenstock J, Foster JA, Kunze WA. The microbiome is essential for normal gut intrinsic primary afferent neuron excitability in the mouse. Neurogastroenterol Motil. 2013;25(2):183-e88.

103. Kashyap PC, et al. Complex interactions among diet, gastrointestinal transit, and gut microbiota in humanized mice. Gastroenterology. 2013;144(5):967-977.

104. Chu H, Mazmanian SK. Innate immune recognition of the microbiota promotes host-microbial symbiosis. Nature Immunol. 2013;14(7):668-675.

105. Prescott D, Lee J, Philpott DJ. An epithelial armamentarium to sense the microbiota. Semin Immunol. 2013;25(5):323-333.

106. Mazmanian SK, Liu CH, Tzianabos AO, Kasper DL. An immunomodulatory molecule of symbiotic bacteria directs maturation of the host immune system. Cell. 2005;122(1):107-118.

107. Barajon I, et al. Toll-like receptors 3,4 , and 7 are expressed in the enteric nervous system and dorsal root ganglia. J Histochem Cytochem. 2009;57(11):1013-1023.

108. Rumio C, et al. Activation of smooth muscle and myenteric plexus cells of jejunum via Toll-like receptor 4. J Cell Physiol. 2006;208(1):47-54.

109. Takeuchi O, Akira S. Pattern recognition receptors and inflammation. Cell. 2010;140(6):805-820.

110. Murakami M, Ohta T, Ito S. Lipopolysaccharides enhance the action of bradykinin in enteric neurons via secretion of interleukin1beta from enteric glial cells. J Neurosci Res. 2009;87(9):2095-2104.

111. Anitha M, Vijay-Kumar M, Sitaraman SV, Gewirtz AT, Srinivasan S. Gut microbial products regulate murine gastrointestinal motility via Toll-like receptor 4 signaling. Gastroenterology. 2012;143(4):1006-1016.

112. Cario E, Gerken G, Podolsky DK. Toll-like receptor 2 controls mucosal inflammation by regulating epithelial barrier function. Gastroenterology. 2007;132(4):1359-1374.

113. Round JL, et al. The Toll-like receptor 2 pathway establishes colonization by a commensal of the human microbiota. Science. 2011;332(6032):974-977.

114. Pierik M, et al. Toll-like receptor-1, -2 , and -6 polymorphisms influence disease extension in inflammatory bowel diseases. Inflamm Bowel Dis. 2006;12(1):1-8

115. Brun P, et al. Toll-like receptor 2 regulates intestinal inflammation by controlling integrity of the enteric nervous system. Gastroenterology. 2013;145(6):1323-1333.

116. Dethlefsen L, Relman DA. Incomplete recovery and individualized responses of the human distal gut microbiota to repeated antibiotic perturbation. Proc Natl Acad Sci U S A. 2011; 108(suppl 1):4554-4561.

117. Nylund L, Satokari R, Salminen S, de Vos WM. Intestinal microbiota during early life impact on health and disease. Proc Nutr Soc. 2014;73(4):457-469.

118. Kamm K, Hoppe S, Breves G, Schroder B, Schemann M. Effects of the probiotic yeast Saccharomyces boulardii on the neurochemistry of myenteric neurones in pig jejunum. Neurogastroenterol Motil. 2004;16(1):53-60.

119. di Giancamillo A, Vitari F, Bosi G, Savoini G, Domeneghini C. The chemical code of porcine enteric neurons and the number of enteric glial cells are altered by dietary probiotics. Neurogastroenterol Motil. 2010;22(9):e271-e278.

120. Verdu EF, et al. Specific probiotic therapy attenu- 
ates antibiotic induced visceral hypersensitivity in mice. Gut. 2006;55(2):182-190.

121. Rousseaux C, et al. Lactobacillus acidophilus modulates intestinal pain and induces opioid and cannabinoid receptors. Nat Med. 2007;13(1):35-37.

122. Bertrand PP, Kunze WA, Bornstein JC, Furness JB, Smith ML. Analysis of the responses of myenteric neurons in the small intestine to chemical stimulation of the mucosa. Am J Physiol. 1997;273(2 pt 1):G422-G435.

123. Soret $\mathrm{R}$, et al. Short-chain fatty acids regulate the enteric neurons and control gastrointestinal motility in rats. Gastroenterology. 2010;138(5):1772-1782.

124. Ward NL, Pieretti A, Dowd SE, Cox SB, Goldstein AM. Intestinal aganglionosis is associated with early and sustained disruption of the colonic microbiome. Neurogastroenterol Motil. 2012;24(9):874-e400.

125. Sasselli V, Boesmans W, Vanden Berghe P, Tissir F, Goffinet AM, Pachnis V. Planar cell polarity genes control the connectivity of enteric neurons.
J Clin Invest. 2013;123(4):1763-1772.

126. Cryan JF, Dinan TG. Mind-altering microorganisms: the impact of the gut microbiota on brain and behaviour. Nat Rev Neurosci. 2012;13(10):701-712.

127. Chaidez V, Hansen RL, Hertz-Picciotto I. Gastrointestinal problems in children with autism, developmental delays or typical development. JAutism Dev Disord. 2014;44(5):1117-1127.

128. Mazefsky CA, Schreiber DR, Olino TM, Minshew NJ. The association between emotional and behavioral problems and gastrointestinal symptoms among children with high-functioning autism. Autism. 2013;18(5):493-501.

129. Schieve LA, et al. Concurrent medical conditions and health care use and needs among children with learning and behavioral developmental disabilities, National Health Interview Survey, 2006-2010. Res Dev Disabil. 2012;33(2):467-476.

130. Hsiao EY, et al. Microbiota modulate behavioral and physiological abnormalities associated with neurodevelopmental disorders. Cell.
2013;155(7):1451-1463.

131. Farache J, Zigmond E, Shakhar G, Jung S. Contributions of dendritic cells and macrophages to intestinal homeostasis and immune defense. Immunol Cell Biol. 2013;91(3):232-239.

132. Eyo UB, Dailey ME. Microglia: key elements in neural development, plasticity, and pathology. J Neuroimmune Pharmacol. 2013;8(3):494-509.

133. Squarzoni P, et al. Microglia modulate wiring of the embryonic forebrain. Cell Rep. 2014;8(5):1271-1279.

134. Mikkelsen HB, Rumessen JJ. Characterization of macrophage-like cells in the external layers of human small and large intestine. Cell Tissue Res. 1992;270(2):273-279.

135. Phillips RJ, Powley TL. Macrophages associated with the intrinsic and extrinsic autonomic innervation of the rat gastrointestinal tract. Auton Neurosci. 2012;169(1):12-27.

136. Muller PA, et al. Crosstalk between muscularis macrophages and enteric neurons regulates gastrointestinal motility. Cell. 2014;158(2):300-313. 